\title{
Responding under variable-interval, variable-time, and extinction schedules in pigeons and crows
}

\author{
ROBERT W. POWELL and LINDA J. PALM \\ University of South Florida, Tampa, Florida 33620
}

\begin{abstract}
Common crows and pigeons were studied successively under variable-interval, variable-time, and extinction schedules. The rate and pattern of keypecking were similar for both species under the variable-interval schedule. While overall response rates did not differ between species under the variable-time schedule, there were major differences in the intrasession and interreinforcement distribution of responses. During the final sessions under this procedure, the crows showed marked within-session attenuation of responding, whereas the pigeons responded consistently throughout the sessions. The second difference, which appeared to be related to the first, involved the frequent occurrence of keypecks in pigeons that were directly elicited by food presentations. The crows never displayed this form of behavior. There was no difference between species in responding under extinction.
\end{abstract}

A response-independent schedule specifies the temporal distribution of positive reinforcers without respect to behavior. These schedules are denoted as fixed time (FT) and variable time (VT) to distinguish them from their response-dependent counterparts, fixed interval (FI) and variable interval (VI). The usual finding with pigeons when the response dependency is removed is that the rate of responding decreases relative to the response-dependent schedule, but it remains well above zero (Edwards, West, \& Jackson, 1968; Herrnstein, 1966; Lowe \& Harzem, 1977). However, it has also been reported that a few pigeons cease responding entirely under response-independent schedules (Zeiler, 1968).

Several years ago, Lowe and Harzem (1977) compared responding in rats and pigeons when they were switched from FI to FT schedules. They reported that responding for the rats decreased to a much greater extent than for the pigeons. They also found that response rate for the pigeons was inversely related to the duration of the interreinforcement interval. Lowe and Harzem attempted to account for these differences principally on the basis of differences in the topography of operant (leverpressing vs. keypecking) and consummatory responses between rats and pigeons. They argued that stimuli that signal food presentation may come to elicit pecking in pigeons (cf. Brown \& Jenkins, 1968; Staddon \& Simmelhag, 1971), but no similar effect has been observed in rats.

Recently, we (Powell \& Kelly, 1979) studied keypecking in fish crows trained under either FI or VI schedules and then switched to FT and VT schedules,

Requests for reprints should be addressed to Robert W. Powell, Department of Psychology, University of South Florida, Tampa, Florida 33620. respectively. Keypecking decreased more rapidly under the VT than under the FT schedule, but eventually all crows ceased responding under both responseindependent schedules. These results appear to differ from the findings obtained with pigeons under similar conditions, but such a conclusion would appear premature because of the effect of the interreinforcement interval demonstrated by Lowe and Harzem (1977).

The present experiment was undertaken to provide a direct comparison of responding in pigeons and crows under a response-independent schedule followed by extinction. A noteworthy consideration in this study was that, unlike a comparison between rats and pigeons, the operant and consummatory responses of pigeons and crows appear to be identical. Consequently, any differences in behavior that did emerge would more likely be attributable to species differences in learning and/or performance.

\section{METHOD}

\section{Subjects}

Four adult white Carneaux pigeons and four adult common crows (Corvus brachyrhynchos), all with experience under a variety of reinforcement schedules, were used. The pigeons were obtained from a commercial supplier in South Carolina and had been maintained in individual cages for approximately 2 years. The crows were obtained from commercial suppliers in Wisconsin and Florida and had been housed in individual cages for 1-3 years. The birds were maintained at approximately $85 \%$ of their freefeeding weights throughout the experiment. All subjects were housed in individual cages with water and grit freely available.

\section{Apparatus}

The apparatus included two standard pigeon test chambers (Lehigh Valley Model 1519C), each containing two translucent response keys. The chamber in which the crows were studied had been modified by enlarging the opening to the food hopper. Otherwise, the chambers were identical. One response key 
remained dark and inoperative. The other key, located on the right-hand side of the intelligence panel, was illuminated by white light and was operated by a force of $15 \mathrm{~g}$ or more. The reinforcer was Top Choice for the crows and Purina Pigeon Checkers for the pigeons. Reinforcement time was $2.5 \mathrm{sec}$ for all birds. During food presentations, the response key was turned off and a 7-W bulb illuminated the food hopper. Constant illumination of the chamber was provided by a $28-\mathrm{V}$ dc houselight. An exhaust fan and a white-noise generator provided ventilation and masking noise. Data were recorded by digital counters and Gebrands cumulative recorders.

\section{Procedure}

Variable interval. All birds were studied under a VI 60 -sec schedule until responding stabilized. The stability criterion was defined by variation in response rates within $\pm 15 \%$ of the mean rate over five consecutive sessions. Experimental sessions were $36 \mathrm{~min}$ in duration throughout the experiment. Relatively short sessions were used in order to minimize satiation effects in the crows.

Variable time. All birds were studied under a VT 60 -sec schedule, with reinforcers presented on the same time basis as under the VI 60 -sec schedule, but with the response contingency eliminated. Exposure to this procedure continued until the stability criterion specified above was met or until 20 sessions were completed.

Extinction. All birds were studied under extinction until a criterion of 50 or fewer responses over five consecutive sessions was met or until 20 sessions were completed.

\section{RESULTS}

\section{Variable Interval}

Mean response rates per session under the three schedules are shown for all subjects in Figure 1. While the pigeons appeared to have somewhat higher and more uniform response rates under the VI 60-sec schedule, a Mann-Whitney $U$ test revealed that there was no difference in response rates between species $(U=4$, $\mathrm{p}=.171)$.

Figure 2 presents representative cumulative records of responding for two crows and two pigeons under the VI schedule. These records show that response patterns for the two species were quite similar, with consistent responding over time, few pauses, and occasional brief fluctuations in rate.

\section{Variable Time}

The change to response-independent reinforcement resulted in an immediate decrease in responding for all birds, as shown in Figure 1. Generally, responding under the VT schedule continued to decrease for both crows and pigeons over the entire 20 sessions. However, one crow (99) and two pigeons $(337,360)$ did develop

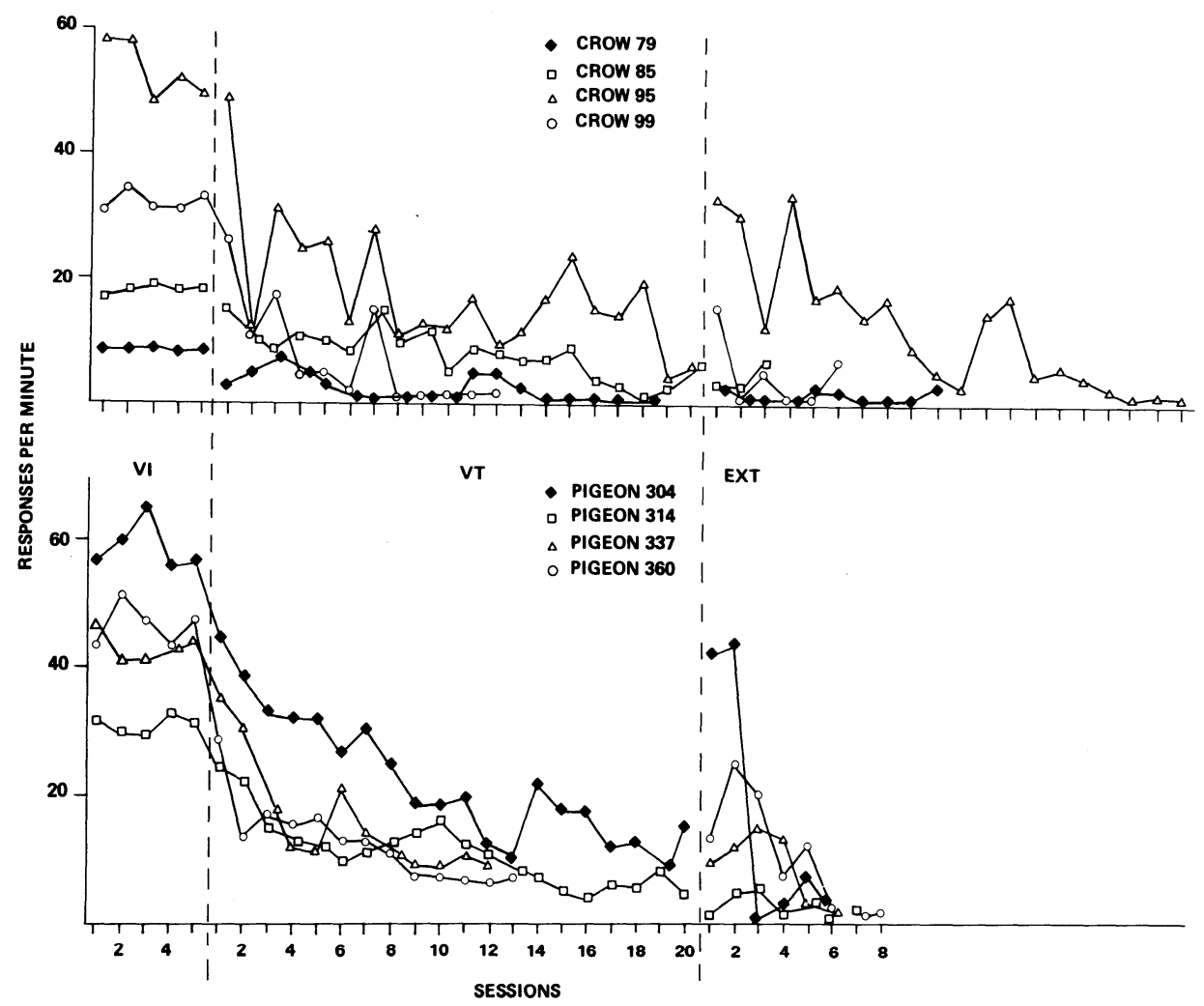

Figure 1. Mean response rates per session for each subject during the final five sessions under the VI schedule, all sessions under the VT schedule, and all sessions under extinction except the last five when the extinction criterion was attained. 


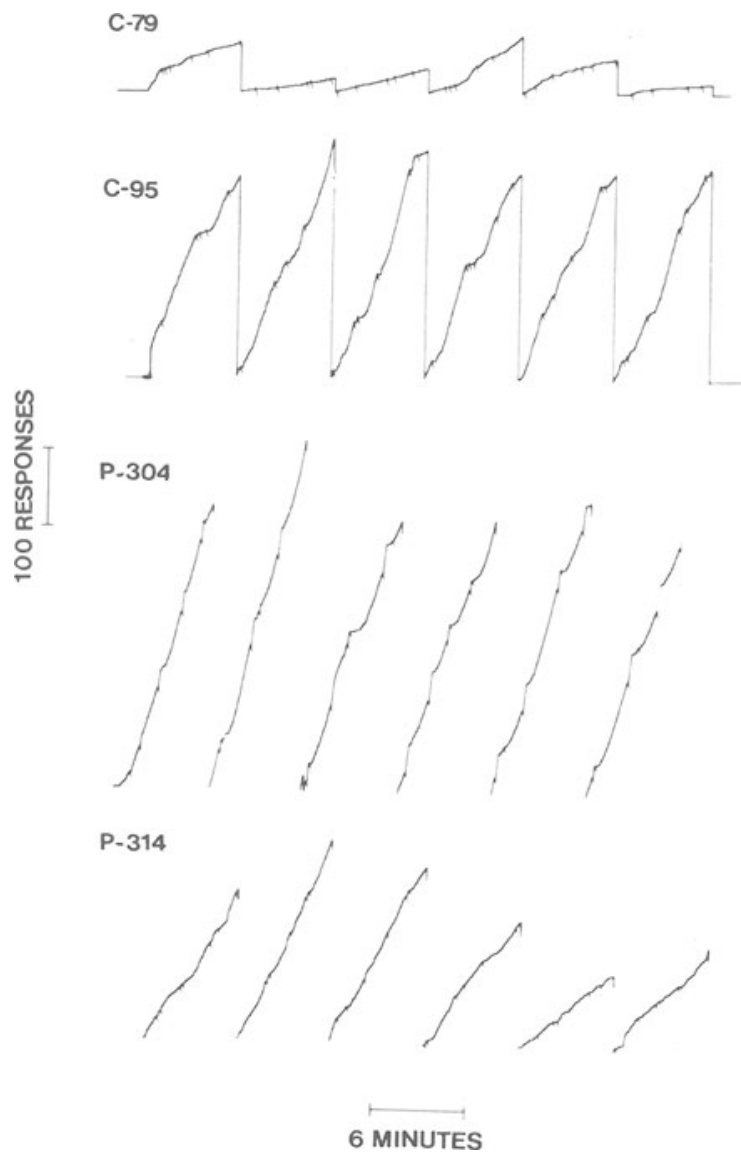

Figure 2. Cumulative records of responding under the VI schedule for two crows and two pigeons. These records show performance for the birds of each species with the highest and lowest rates of response.

stable response rates under this procedure and, consequently, were not studied for the entire 20 sessions. A Mann-Whitney $U$ test that compared terminal response rates revealed that there was no difference between species in either absolute $(\mathrm{U}=2, \mathrm{p}=.057)$ or relative response rates $(\mathrm{U}=3, \mathrm{p}=.10)$ produced by this procedure.

Figure 3 presents representative cumulative records of responding for two crows and two pigeons under the VT schedule. Examination of these records reveals that while the species did not differ in overall response rates, there were clear differences in other dimensions of behavior. One notable feature was a consistent decline in responding over each session for the crows; the pigeons tended to maintain constant response rates over a session. A Mann-Whitney $U$ test that compared the proportion of responses occurring in the first half of the session between species revealed that the crows had significantly higher percentages than the pigeons $(U=1$, $\mathrm{p}=.029$ ). Perhaps more convincing than this statistical analysis was the fact that three crows made $91.2 \%$ (C79), 91.1\% (C85), and 83.4\% (C95) of their responses during the first half of these sessions, whereas the largest disproportion for the pigeons was 54.5\% (P337). While this same effect had not been apparent in the cumulative records of responding under the VI schedule, it nevertheless seemed appropriate to conduct a statistical analysis of terminal response rates under that procedure. A Mann-Whitney $U$ test that compared disproportionality of responding within sessions between crows and pigeons revealed no difference between species $(U=7, p=.443)$.

The second notable feature of behavior revealed in the cumulative records was bursts of responding by the pigeons that occurred immediately after the presentation of a reinforcer. For purpose of quantification, a "burst" was defined as five or more responses in the first $5 \mathrm{sec}$ after reinforcement. During the final five sessions under the VT schedule, such response bursts were observed following 19.4\% (Pigeon 337), 45.6\% (Pigeon 314), $59.4 \%$ (Pigeon 360), and 62.2\% (Pigeon 304) of the reinforcer presentations for the pigeons. The crows displayed no bursts of responding under the VT schedule. These bursts often involved 20-30 responses for Pigeons 304 and 360, and these birds rarely responded except immediately after a reinforcer was presented.

\section{Extinction}

All birds except Crow 95 met the extinction criterion of 50 or fewer responses in each of five consecutive sessions. A Mann-Whitney $U$ test that compared number of sessions to criterion indicated no difference between species $(U=7, p=.443)$. During the initial extinction sessions, several birds (Pigeons 360 and 304 and Crow 95) showed marked increases in responding over the rate that had existed during the final sessions under the VT schedule.

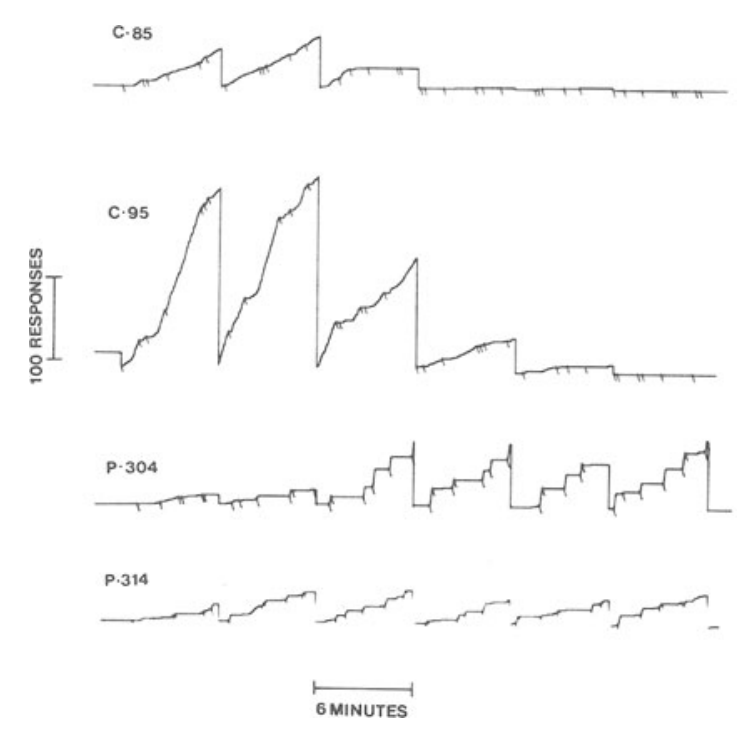

Figure 3. Cumulative records of responding under the VT schedule for two crows and two pigeons. 


\section{DISCUSSION}

The present results show a clear difference in the pecking behavior of crows and pigeons when reinforcement is presented independently of responding at varied time intervals. While there was no difference between species in overall response rates under the VT schedule, major differences were noted both in the distribution of responses over an experimental session and in the distribution of responses between successive reinforcers. For the pigeons, pecking appeared to be largely elicited by the presentation of food, since most responses occurred in bursts immediately after the delivery of a reinforcer. There have been many previous demonstrations that pecking in pigeons may be directly elicited by food and also by stimuli associated with food (Brown \& Jenkins, 1968; Lowe \& Harzem, 1977; Staddon \& Simmelhag, 1971). Pecking for crows under the VT schedule tended to be uniformly distributed between reinforcers, as long as it continued.

The second difference between species, that involving the within-session distribution of responses under the responseindependent schedule, appeared to be at least partially related to the phenomenon of reinforcer-elicited responding. It would appear that responding in pigeons remained fairly uniform over a session, because the reinforcers that elicited the majority of responses were distributed uniformly over time. On the other hand, the crows showed clear within-session attenuation of responding under the same conditions. For the crows, pecking appeared to extinguish over the course of a session, and then spontaneous recovery occurred at the beginning of the next session.

These differences do not seem to be related to performance under the VI schedule, under which the crows and pigeons behaved quite similarly in terms of both the rate and pattern of response. The results obtained for the crows under this procedure replicate the findings obtained in an earlier study (Powell, 1972). There was also no difference between species in responding under extinction. All of the birds showed the gradual, but sometimes erratic, decline in responding over sessions, that is typical under this procedure (Lattal, 1972).

It now seems clear that Skinner (1938) erred in selecting keypecking in pigeons as an "arbitrary" operant, for while he sought a response that was not intrinsically related to the reinforcer, he chose one that was. The well-known experiment by Staddon and Simmelhag (1971) provided massive evidence of the ubiquitousness of pecking by pigeons in the presence of food, as well as the relative unimportance of the response-reinforcer contingency in governing this behavior. The numerous demonstrations of autoshaping in pigeons provide evidence to these same points (see Schwartz \& Gamzu, 1977, for a review).

The pigeon has been used extensively in the experimental analysis of behavior, very often in experiments that purport to examine the effects of various contingencies that are arranged between behavior and reinforcers. The present results, as well as those cited above, suggest that the pigeon may be an inappropriate subject to use in this type of analysis, because its pecking behavior will be concurrently influenced by both response-elicitation and response-reinforcement mechanisms. Presently, there is no way to discriminate between responses that are attributable to these two sources of control when they are simultaneously present.

Several of the differences in responding between crows and pigeons, which we have reported in earlier studies, appear to be explainable on the basis of differences between species in responses elicited by reinforcer presentations. Pigeons typically show a direct relationship between response rate and reinforcement rate under interval schedules (Catania \& Reynolds, 1968), whereas crows respond at relatively constant rates across a range of FI and VI values (Powell, 1972, 1973; Powell \& Kelly, 1979). Of particular note are the much lower FI response rates in crows compared with pigeons. The crows typically wait much longer into the interval and often make just a small number of responses prior to the reinforcer (Powell, 1972, 1973).

The high FI response rates of pigeons, which, in a sense, constitute wasted effort, have always been difficult to explain Lowe and Harzem (1977) reported that rats, like crows, show considerably more efficient performance under FI schedules than do pigeons. They proposed that this difference was a result of pecking's being a consummatory response in pigeons, whereas leverpressing in rats is not. Consequently, the rate of pecking in pigeons is enhanced by food-elicited pecks that become conditioned to temporal factors whenever food is presented regularly in time. No similar enhancement of responding occurs in either rats or crows. The present results support Lowe and Harzem's explanation and also question again the generality of results obtained from pigeons in conditioning experiments. These results probably extend only to other species and situations wherein the operant and consummatory responses for the animal under study are essentially identical.

\section{REFERENCES}

Brown, P. L., \& Jenkins, H. M. Auto-shaping of the pigeon's keypecking. Journal of the Experimental Analysis of Behavior, 1968, 11, 1-8.

Catania, A. C., \& Reynolds, G. S. A quantitative analysis of the responding maintained by interval schedules of reinforcement. Journal of the Experimental Analysis of Behavior, 1968, 11, 327-383.

Edwards, D. D., West, J. R., \& Jackson, V. The role of contingencies in the control of behavior. Psychonomic Science, $1968,10,39-40$.

Herrnstein, R. J. Superstition: A corollary of the principles of operant conditioning. In W. K. Honig (Ed.), Operant behavior: Areas of research and application. New York: AppletonCentury-Crofts, 1966.

LATtAL, K. A. Response-reinforcer independence and conventional extinction after fixed-interval and variable-interval schedules. Journal of the Experimental Analysis of Behavior, 1972, 18, 133-140.

Lowe, C. F., \& HARzem, P. Species differences in temporal control of behavior. Journal of the Experimental Analysis of Behavior, 1977, 38, 189-201.

Powell, R. W. Responding under basic schedules of reinforcement in the crow. Journal of Comparative and Physiological Psychology, 1972, 79, 156-164.

Powell, R. W. Time-based responding in pigeons and crows. Auk, 1973, 90, 803-808.

Powell, R. W., \& Kelly, W. A. Crows learn not to respond under response-independent reinforcement. Bulletin of the Psychonomic Society, 1979, 13, 397-400.

Schwartz, B., \& Gamzu, E. Pavlovian control of operant behavior: An analysis of autoshaping and its implications for operant conditioning. In W. K. Honig \& J. E. R. Staddon (Eds.), Handbook of operant behavior. Englewood Cliffs, N.J: Prentice-Hall, 1977.

Skinner, B. F. The behavior of organisms. New York: AppletonCentury-Crofts, 1938.

Staddon, J. E. R., \& Simmelhag, V. L. The superstition experiment: A reexamination of its implications for the principles of adaptive behavior. Psychological Review, 1971, 78, 3-43.

ZE ILE R, M. Fixed and variable schedules of response-independent reinforcement. Journal of the Experimental Analysis of Behavior, 1968, 11, 405-414.

(Received for publication October 17, 1981.) 